\title{
Carotenoid determination in tomato juice using near infrared spectroscopy**
}

\author{
Konrád Deák ${ }^{1}$,Tamás Szigedi ${ }^{2}$ Zoltán Pék ${ }^{1}$, Piotr Baranowski ${ }^{3 *}$, and Lajos Helyes ${ }^{1}$ \\ ${ }^{1}$ Szent István University, Institute of Horticulture, Páter K. út 1., H-2100 Gödöllő, Hungary \\ ${ }^{2}$ Wekerle Sándor Üzleti Főiskola, Jázmin utca 10., H-1083 Budapest, Hungary \\ ${ }^{3}$ Institute of Agrophysics, Polish Academy of Sciences, Doświadczalna 4, 20-290 Lublin, Poland
}

Received December 28, 2014; accepted May 26, 2015

\begin{abstract}
A b s t r a c t. A rapid non-destructive method for profiling tomato carotenoids was developed using NIR spectrometry. One hundred and twenty tomato samples were produced at the Experimental Farm of Szent István University in Gödöllő (Hungary). The sample preparation was based on homogenization. The mixed samples were scanned with a diode array Perten DA7200 NIR Analyzer (950-1650 nm) and analyzed by high performance liquid chromatography. The calibration was based on partial least squares regression with cross-validation. The performance of the final model was evaluated according to root mean square error of cross-validation. The results indicate that the main carotenoid components were accurately predicted. The correlation between the NIR measurement and the $\beta$-carotene content of tomatoes was adequately high $\left[\mathrm{R}^{2} \mathrm{CV}=0.89\right.$; root mean square error of cross-validation $\left.=0.174 \mu \mathrm{g} \mathrm{g}^{-1}\right]$. The NIR method was also performed for the determination of the all-trans lycopene content $\left(\mathrm{R}^{2} \mathrm{CV}=0.75\right.$; root mean square error of cross-validation $\left.=6.88 \mu \mathrm{g} \mathrm{g}^{-1}\right)$. It can be concluded that the diode array NIR spectrometer has the potential to be used for the determination of the main carotenoids of tomatoes.

$\mathrm{K}$ e y w o r d s: tomato, carotenoid composition, near-infrared spectroscopy, partial least squares regression
\end{abstract}

\section{INTRODUCTION}

Tomato (Solanum lycopersicum) and tomato-based products are increasingly becoming a significant component of the human diet worldwide and are associated with reduced risks of some types of cancer and cardiovascular diseases (Clinton, 1998). These beneficial properties appear to be related to antioxidants, mainly carotenoids. Carotenoids are ubiquitous organic molecules, but the human body does not synthesise them (Fiedor and Burda, 2014) especially in the context of the anti- and pro-oxidant activity of carotenoids, which, although not synthesized by humans and animals,

*Corresponding author e-mail: pbaranow@ipan.lublin.pl

**This study was funded in part by Kutató Kari Kiválósági Támogatás - Research Centre of Excellence-9878/2015/FEKUT. Szent István University and KTIA_AIK_12-1-2012-0012 project. are also present in their blood and tissues, contributing to a number of biochemical processes. The antioxidant potential of carotenoids is of particular significance to human health, due to the fact that losing antioxidant-reactive oxygen species balance results in 'oxidative stress', a critical factor of the pathogenic processes of various chronic disorders. Data coming from epidemiological studies and clinical trials strongly support the observation that adequate carotenoid supplementation may significantly reduce the risk of several disorders mediated by reactive oxygen species. Here, we would like to highlight the beneficial (protective).

The carotenoid composition of tomatoes is complex and very difficult to assess. Carotenoids are a group of pigments, varying from yellow to red in colour, which are widely distributed in vegetables (Karrer and Jucker, 1950). They also accumulate during the ripening process of tomato (Brandt et al., 2006; Helyes et al., 2006b; Pék et al., 2010). More than 750 carotenoids have been isolated from different plant sources and more than 100 have been found in fruits and vegetables (Britton et al., 2004).

Lycopene is well known as a predominant carotene in tomatoes, accounting for from 65 to $98 \%$ of the total carotenoid content, depending on the cultivar (Mercadante, 2008). It is assumed that $85 \%$ of the dietary lycopene is provided by tomatoes and related products such as tomato juice, ketchup, or tomato paste (Rao and Rao, 2007). Lycopene is followed by $\beta$-carotene, zeaxanthin, lycoxanthin as well as several minor carotenoids in tomatoes (Beecher, 1998). Recently, lycopene has been studied intensively in vitro and in vivo with epidemiological methods because of its marked antioxidant characteristics and an unquestionable role in the prevention of several diseases (Matos et al., 2000). $\beta$-carotene plays a crucial role in human health since it is a major source of vitamin A (Francis, 2002). That

(C) 2015 Institute of Agrophysics, Polish Academy of Sciences 
is why there has been continuous increasing interest in the carotenoid content in tomato and tomato-based product in recent years. Analytical quantification of these components is destructive as well as time- and labour-consuming. Therefore, researchers try to develop a non-destructive and rapid method to assess the fruit quality. Non-destructive colour measuring of tomato fruits in visible (VIS) reflectance spectra showed a good correlation with lycopene (Pék et al., 2014) and $\beta$-carotene (Borghesi et al., 2011) content also, but did not result in exact quantification thereof.

In recent decades, the application of VIS and near infrared (NIR) spectrometry to vegetables and fruits has become more popular for quality and composition studies. Among the non-destructive methods applied in agriculture, near infrared spectroscopy is probably the most studied and accomplished one. Numbers of studies have investigated the potential of VIS/NIR technology for assessing quality parameters of vegetable products including carrot (Belie et al. 2003), Brassica oleracea varieties (Szigedi et al., 2012), and tomatoes (Jha and Matsuoka, 2004; Szuvandzsiev et al., 2014).

In NIR spectrometry, being an indirect analytical method, calibration has to be carried out before performing routine analysis. During calibration, a correlation of the NIR spectra and the chemical/physical parameters in question (recently determined by the reference method) is searched for by means of different regression methods such as: principal component regression (PCR), partial least squares regression (PLS), multiple linear regression (MLR), and artificial neural network (ANN) (Bart et al., 2007).

Rapid spectroscopy methods for the evaluation of carotenoids have been developed with the NIR technique, especially focused on lycopene (Oliveira, 2014; Saad et al., 2014). Rubio-Diaz et al. (2010) were also successful in non-destructive measuring the carotenoid composition with infrared spectroscopy in tomatoes. A VIS/NIR reflectance spectrum is suitable for quantification of ingredients, with not a close correlation between the colourful pigments (Szuvandzsiev et al., 2014).

Tomatoes and tomato based-products are a main source of lycopene for humans, so modern diet needs to develop rapid and cheap techniques for carotenoid measurement. Therefore, the main aim of the present study was to evaluate the ability of NIRS to predict the carotenoid composition of tomato juice samples.

\section{MATERIALS AND METHODS}

An open field experiment of processing tomato was carried out at the Experimental Farm of the Institute of

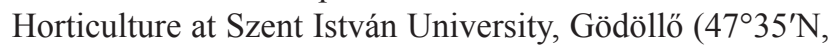
$19^{\circ} 21^{\prime} \mathrm{E}$ ), Hungary, in 2013. The growing technology was the same as that used in the preceding processing tomato experiment (Helyes et al., 2012). There were four different processing tomato hybrids planted out: Uno Rosso F1 (UR),
Triple Red F1 (TR), Strombolino F1 (ST), and Red Code F1 (RC). Irrigation was applied by drip irrigation in three treatments: $100 \%$ optimum water supply (100), $75 \%$ water supply (75), 50\% water supply (50) versus rainfed crops (K). Optimum water supply was calculated from daily potential evapotranspiration of tomato (Pék et al., 2014), based on weather forecasting data of the Hungarian Meteorological Service. Water availability of 596, 502, 404, and $219 \mathrm{~mm}$ were usable for plants in the treatments respectively during the vegetative period. All treatments were additionally treated with $25 \mathrm{~g} / \mathrm{seedling}$ Symbivit ${ }^{\circ}$ (AGRO.bio Hungary Kft. Szombathely, Hungary) arbuscular mycorrhizal (AM) fungi (natural plant growth enhancer) resulting in 30 different varieties/treatment combinations (Table 1). Five fruits and four repetitions in each treatment were harvested by hand in the red ripe stage on the 21 st of August 2013.

Fruits from each repetition were washed, cut, and mixed and the juice samples were refrigerated at $-18^{\circ} \mathrm{C}$ until analysis. Tomato juice samples were scanned using a diode array Perten DA7200 (Perten Instruments, ForrLab Kft., Budapest, Hungary) NIR Analyzer. The spectral resolution was $2 \mathrm{~nm}$. The mixed samples were fitted in a $75 \mathrm{~mm}$ diameter rotation cup and the spectra were collected in reflectance mode. The diode array detector working in the 950-1650 $\mathrm{nm}$ wavelength range combined with Unscrambler 10.3 (CAMO Software AS., Oslo, Norway) software package for multivariate calibration.

The reference method was performed by high performance liquid chromatography (HPLC). To analyze carotenoid type compounds, a Beckman liquid chromatograph consisting of a model Gold System 116 M pump, a model 165 variable wavelength UV-visible detector, and a model 340 organizer equipped with a $20 \mu \mathrm{l}$ loop injector was used. The separation was performed on Chromsil-C18 (240x4.6 mm i.d.) $6 \mu \mathrm{m}$ column using 2:1:1 acetonitrile2-propanolmethanol as the mobile phase at a flow rate of 0.9-1.2 $\mathrm{ml} \mathrm{min}^{-1}$ (Biacs and Daood, 1994). The column effluents were detected at $480 \mathrm{~nm}$, and the signals were recorded by a Shimadzu C-R3A integrator. The samples were analysed in duplicate and standard error of laboratory (SEL) was calculated from these duplicates.

Pre-processing of spectral data is often of vital importance if reasonable results are to be obtained whether the analysis is concerned with exploratory data mining, classification, or building a good robust prediction model (Rinnan et al., 2009). Several signal pre-processing methods were tested in order to find the optimal calibration model for carotenoid content: the first and second derivative (Savitzky-Golay filter), multiplicative scattering correction (MSC), standard normal variate (SNV), and their combinations. The data were evaluated by PLS regression and the optimal calibration model for each constituent was developed by cross-validation. The correct number of regression factors for the PLS model was determined by the lowest root mean square error of cross validation. 
T a b l e 1. Average value of carotenoids $\left(\mathrm{mg} \mathrm{kg}^{-1}\right)$ in tomato fruit fresh weight from different varieties/treatment combinations $(\mathrm{n}=4, \pm \mathrm{SD})$

\begin{tabular}{|c|c|c|c|c|c|}
\hline Treatment & All-trans lycopene & $\begin{array}{c}\text { Cis-lycopene } \\
\text { diepoxide }\end{array}$ & Lycoxanthin & Zeaxanthin & $\beta$-carotene \\
\hline \multicolumn{6}{|c|}{ Uno Rosso F1 (UR) } \\
\hline $\mathrm{K}$ & $59.6 \pm 22.74$ & $0.98 \pm 0.13$ & $1.69 \pm 0.42$ & $0.70 \pm 0.17$ & $0.81 \pm 0.33$ \\
\hline 50 & $78.43 \pm 9.04$ & $1.01 \pm 0.10$ & $1.23 \pm 0.24$ & $0.35 \pm 0.04$ & $0.93 \pm 0.23$ \\
\hline 75 & $80.38 \pm 0.79$ & $1.11 \pm 0.08$ & $1.07 \pm 0.06$ & $0.33 \pm 0.04$ & $1.07 \pm 0.14$ \\
\hline 100 & $69.38 \pm 13.23$ & $1.45 \pm 0.58$ & $0.91 \pm 0.27$ & $0.26 \pm 0.05$ & $0.86 \pm 0.09$ \\
\hline KM & $75.86 \pm 1.60$ & $1.23 \pm 0.11$ & $1.73 \pm 0.26$ & $0.69 \pm 0.12$ & $0.84 \pm 0.09$ \\
\hline $50 \mathrm{M}$ & $73.17 \pm 15.08$ & $0.79 \pm 0.31$ & $1.25 \pm 0.36$ & $0.45 \pm 0.10$ & $0.91 \pm 0.14$ \\
\hline $75 \mathrm{M}$ & $90.77 \pm 9.03$ & $1.07 \pm 0.33$ & $1.54 \pm 0.25$ & $0.41 \pm 0.03$ & $1.34 \pm 0.11$ \\
\hline $100 \mathrm{M}$ & $89.38 \pm 4.34$ & $2.63 \pm 0.56$ & $1.30 \pm 0.14$ & $0.38 \pm 0.03$ & $1.28 \pm 0.13$ \\
\hline Range & $31.5-103.9$ & $0.38-3.28$ & $0.54-2.32$ & $0.21-0.94$ & $0.49-1.47$ \\
\hline Mean & 77.1 & 1.28 & 1.34 & 0.45 & 1.01 \\
\hline \multicolumn{6}{|c|}{ Triple Red F1 (TR) } \\
\hline $\mathrm{K}$ & $77.85 \pm 3.97$ & $0.98 \pm 0.05$ & $3.00 \pm 0.29$ & $0.82 \pm 0.21$ & $1.97 \pm 0.30$ \\
\hline 50 & $52.9 \pm 13.08$ & $0.62 \pm 0.11$ & $1.34 \pm 0.37$ & $0.4 \pm 0.03$ & $1.58 \pm 0.31$ \\
\hline 75 & $74.12 \pm 8.91$ & $0.95 \pm 0.22$ & $1.78 \pm 0.19$ & $0.57 \pm 0.1$ & $2.40 \pm 0.42$ \\
\hline 100 & $65.59 \pm 10.19$ & $0.66 \pm 0.17$ & $1.22 \pm 0.18$ & $0.33 \pm 0.05$ & $1.93 \pm 0.19$ \\
\hline KM & $46.48 \pm 2.47$ & $0.75 \pm 0.04$ & $2.03 \pm 0.21$ & $0.62 \pm 0.06$ & $1.31 \pm 0.22$ \\
\hline $50 \mathrm{M}$ & $44.27 \pm 8.12$ & $0.71 \pm 0.11$ & $1.21 \pm 0.22$ & $0.50 \pm 0.10$ & $1.46 \pm 0.08$ \\
\hline $75 \mathrm{M}$ & $55.78 \pm 6.73$ & $0.83 \pm 0.10$ & $1.21 \pm 0.08$ & $0.52 \pm 0.10$ & $1.93 \pm 0.32$ \\
\hline $100 \mathrm{M}$ & $86.97 \pm 11.61$ & $1.22 \pm 0.34$ & $1.89 \pm 0.18$ & $0.55 \pm 0.10$ & $2.81 \pm 0.57$ \\
\hline Range & $37.2-103.2$ & $0.41-1.72$ & $0.85-3.33$ & $0.29-0.95$ & $1.13-3.48$ \\
\hline Mean & 63.0 & 0.84 & 1.71 & 0.54 & 1.92 \\
\hline \multicolumn{6}{|c|}{ Strombolino F1 (ST) } \\
\hline $\mathrm{K}$ & $94.47 \pm 6.85$ & $1.7 \pm 0.33$ & $1.32 \pm 0.13$ & $0.63 \pm 0.09$ & $1.63 \pm 0.44$ \\
\hline 50 & $106.72 \pm 2.87$ & $1.3 \pm 0.1$ & $1.23 \pm 0.05$ & $0.24 \pm 0.02$ & $1.92 \pm 0.41$ \\
\hline 100 & $98.2 \pm 4.89$ & $0.52 \pm 0.41$ & $1.08 \pm 0.09$ & $0.29 \pm 0.05$ & $2.49 \pm 0.34$ \\
\hline KM & $90.45 \pm 7.34$ & $1.58 \pm 0.28$ & $1.15 \pm 0.13$ & $0.74 \pm 0.23$ & $1.5 \pm 0.25$ \\
\hline $50 \mathrm{M}$ & $82.6 \pm 10.74$ & $1.05 \pm 0.15$ & $1.02 \pm 0.16$ & $0.35 \pm 0.06$ & $2.19 \pm 0.37$ \\
\hline $100 \mathrm{M}$ & $92.58 \pm 15.2$ & $1.52 \pm 0.61$ & $1.25 \pm 0.34$ & $0.14 \pm 0.19$ & $3.26 \pm 0.56$ \\
\hline Range & $69.5-109.2$ & $0.25-2.19$ & $0.83-1.59$ & 0.01-0.96 & $1.2-3.87$ \\
\hline Mean & 94.2 & 1.28 & 1.17 & 0.40 & 2.17 \\
\hline
\end{tabular}

$\mathrm{K}$ - versus rainfed crops, $50-50 \%, 75$ - 75\% water supply, $100-100 \%$ optimum water supply, AM - arbuscular mycorrhizal fungi. 
T a b l e 1. Continuation

\begin{tabular}{cccccc}
\hline Treatment & All-trans lycopene & $\begin{array}{c}\text { Cis-lycopene } \\
\text { diepoxide }\end{array}$ & Lycoxanthin & Zeaxanthin & $\beta$-carotene \\
\hline RCK & $86.01 \pm 8.29$ & $2.3 \pm 0.3$ & $2.12 \pm 0.31$ & $0.64 \pm 0.15$ & $0.74 \pm 0.12$ \\
RC50 & $79.33 \pm 5.37$ & $2.14 \pm 0.19$ & $1.42 \pm 0.22$ & $0.54 \pm 0.12$ & $0.92 \pm 0.15$ \\
RC75 & $75.93 \pm 10.04$ & $1.41 \pm 0.42$ & $1.36 \pm 0.14$ & $0.36 \pm 0.08$ & $1.13 \pm 0.11$ \\
RC100 & $58.38 \pm 8.39$ & $0.59 \pm 0.23$ & $1.22 \pm 0.16$ & $0.28 \pm 0.03$ & $1.9 \pm 0.32$ \\
RCKM & $77.67 \pm 4.6$ & $1.72 \pm 0.49$ & $1.93 \pm 0.21$ & $0.74 \pm 0.04$ & $0.76 \pm 0.02$ \\
RC50M & $79.49 \pm 4.84$ & $1.88 \pm 0.08$ & $1.41 \pm 0.23$ & $0.58 \pm 0.15$ & $1.03 \pm 0.17$ \\
RC75M & $86.79 \pm 5.86$ & $1.34 \pm 0.06$ & $1.5 \pm 0.03$ & $0.4 \pm 0.08$ & $1.04 \pm 0.13$ \\
RC100M & $48.63 \pm 8.98$ & $0.63 \pm 0.19$ & $0.98 \pm 0.25$ & $0.18 \pm 0.02$ & $1.48 \pm 0.2$ \\
Range & $40.4-95.1$ & $0.26-2.51$ & $0.79-2.3$ & $0.16-0.82$ & $0.56-2.24$ \\
Mean & 74.0 & 1.50 & 1.49 & 0.47 & 1.12 \\
\hline
\end{tabular}

\section{RESULTS AND DISCUSSION}

Figure 1 shows the cumulated reflectance spectra of the tomato juice samples. The four varieties have similar spectra with two reflectance peaks identified around 1080 and $1280 \mathrm{~nm}$. The typical absorption bands related to the high water-content of tomato samples can be seen around 980 (Flores et al., 2009), and two sugar-related peaks appear also in the spectrum around 1200 and $1410 \mathrm{~nm}$. Similar absorption bands were reported in the studies of apricot, tomato, and passion fruit (Oliveira, 2014).

In the NIR region, there was a local absorption maximum at around $980 \mathrm{~nm}$ (Tiwari et al., 2013). The treatments were discriminated by the different average values of the reflectance spectra. The values are in decreasing order of $\mathrm{K}, 50,75,100$, the order of 100 and $100 \mathrm{M}$ was alternating, the higher the water supply the lower the reflectance spectra were in every variety regardless of the variety (Szuvandzsiev et al., 2014).

The results of the reference analysis for the full set are listed in Table 1. The results reveal a broad range in the carotenoid composition in the calibration set. According to Helyes et al. (2006a), the lycopene content of sixteen different tomato varieties in Hungary ranged between 39 and $171 \mu \mathrm{g} \mathrm{g}^{-1}$. In our case, the actual all-trans lycopene content of the samples was found to be in the range of 31.5$109.2 \mu \mathrm{g} \mathrm{g}^{-1}$ and the $\beta$-carotene content was in the range of 0.49-3.87 $\mu \mathrm{g} \mathrm{g}^{-1}$ by the HPLC determination.

During PLS regression, four different spectral pretreatments were applied to set out the typical absorption peaks of the spectra. The results of PLS and the applied pre-treatment are summarized in Table 2 for each consti- tuent. Concerning the NIR analyses and the mathematical evaluation of the spectra, the optimal equations were found by applying the first derivative + MSC and second derivative mathematical pre-processing in all analyses similarly to Pedro and Ferreira (2007).

The lowest RMSECV of the all-trans lycopene content was achieved by considering two PLS factors and the first derivative + MSC pre-treatment. The correlation between the NIR measurement and the all-trans lycopene content of tomatoes was adequately high $\left(\mathrm{R}^{2} \mathrm{CV}=0.75\right.$; $\mathrm{RMSECV}=$ $\left.6.88 \mu \mathrm{g} \mathrm{g}^{-1}\right)$. Baranska et al. (2006) $\left(\mathrm{R}^{2} \mathrm{CV}=0.927\right.$, RMSECV $=8.64 \mu \mathrm{g} \mathrm{g}^{-1}$ ) and Tianhua et al. (2013) performed a similar experiment but the size of the sample set used in that report was much smaller (28 samples were used) and the SECV

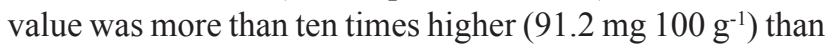
in our study. Pedro and Ferreira (2005) applied NIR spectra $(1000-2500 \mathrm{~nm})$ and multivariate calibration to evaluate lycopene and $\beta$-carotene contents of tomato. They found better results using a spectra-splitting approach, using MSC than the second derivative pre-treatments. After PLS-1 calibration, the prediction accuracy $r$ values were over 0.99 , between 1250-1 $667 \mathrm{~nm}$ of split spectra.

Earlier literature reports did not reveal any correlations between NIR spectral characteristics and cis-lycopene diepoxide, lycoxanthin, and zeaxanthin contents. The present study reveals that such a correlation exists. In Fig. 2, the scatter plot of references measured and predicted using NIRS with PLS models in the calibration set is presented. A correlation was performed using the first derivative + MSC spectral transformation of the samples for the determination of cis-lycopene diepoxide. The statistical parameters 

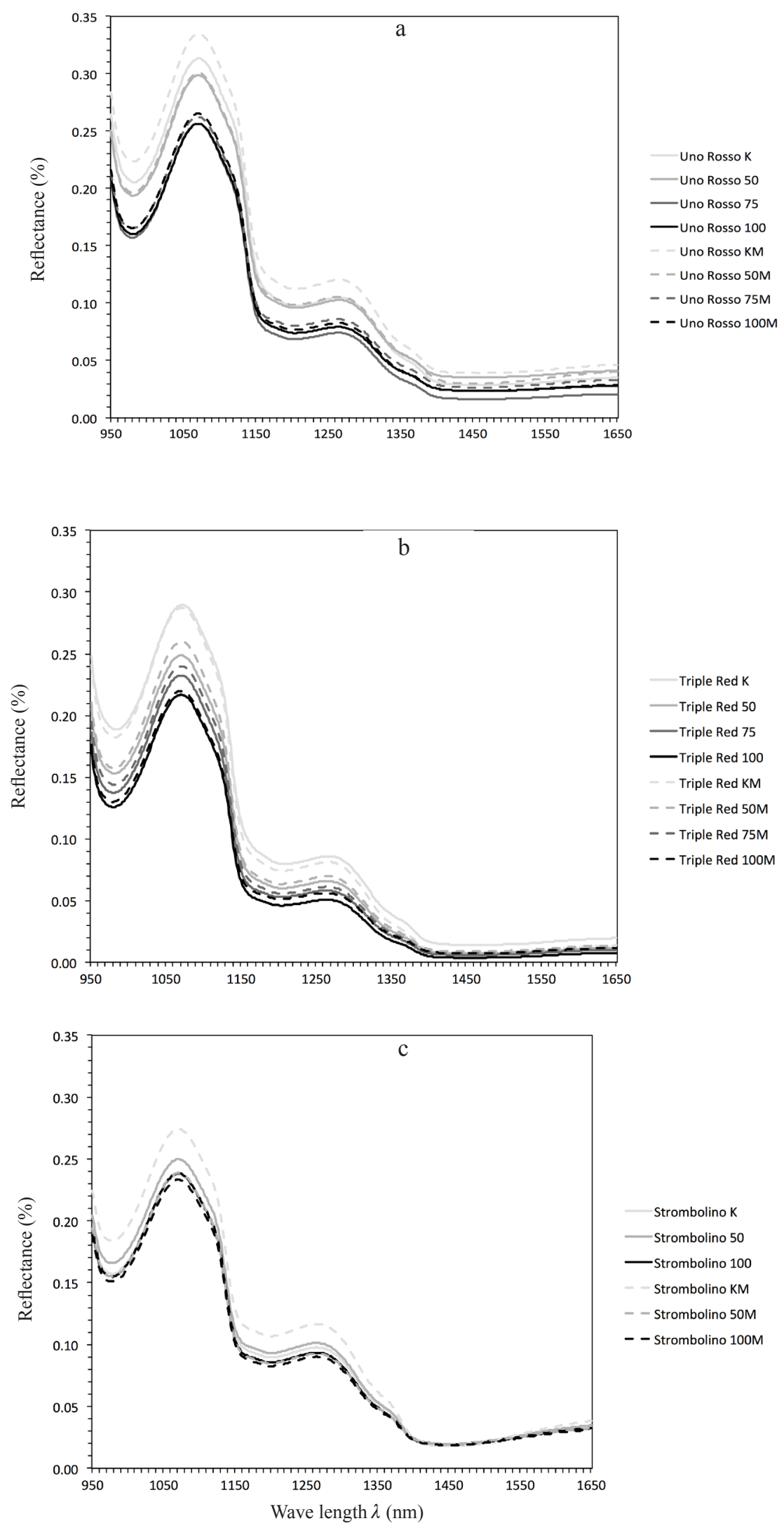

Fig. 1. Average NIR (950-1 $650 \mathrm{~nm})$ reflectance spectra of tomato juice samples from different cultivar/treatment combinations $(\mathrm{n}=4)$ : $a-U R$ variants, $b-T R$ variants, $c-S T$ variants, $d-R C$ variants. 


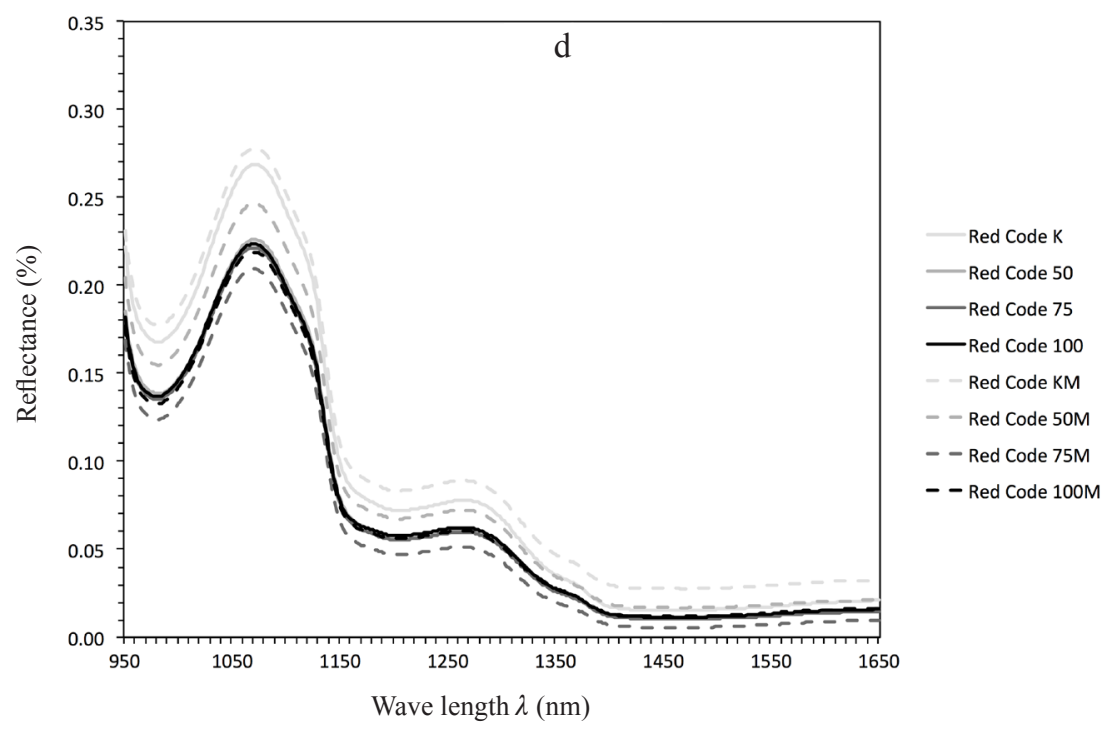

Fig. 1. Continuation.

T a b l e 2. Parameters of the carotenoid calibration

\begin{tabular}{|c|c|c|c|c|c|}
\hline \multirow{2}{*}{ Pretreatment } & All-trans lycopene & $\begin{array}{l}\text { Cis-lycopene } \\
\text { diepoxide }\end{array}$ & Lycoxanthin & Zeaxanthin & $\beta$-carotene \\
\hline & \multicolumn{4}{|c|}{ 1st derivative $+\mathrm{MSC}$} & 2nd derivative \\
\hline Wavelength range & \multicolumn{4}{|c|}{$950-1650$} & $950-1300$ \\
\hline $\mathrm{R}_{\mathrm{C}}^{2}$ & 0.78 & 0.83 & 0.88 & 0.83 & 0.90 \\
\hline RMSEC & 6.68 & 0.232 & 0.247 & 0.086 & 0.166 \\
\hline RPD & 2.11 & 2.46 & 2.93 & 2.42 & 3.18 \\
\hline $\mathrm{R}_{\mathrm{CV}}^{2}$ & 0.75 & 0.76 & 0.84 & 0.75 & 0.89 \\
\hline RMSECV & 6.88 & 0.269 & 0.281 & 0.099 & 0.174 \\
\hline RPD & 2.02 & 2.04 & 2.49 & 2.01 & 2.95 \\
\hline BIAS & -0.1150 & -0.0006 & 0.0007 & 0.0011 & 0.0014 \\
\hline Numbers of PLS & 2 & 8 & 7 & 7 & 4 \\
\hline
\end{tabular}

$\mathrm{R}_{\mathrm{C}}^{2}: \mathrm{R}^{2}$ calibration; $\mathrm{R}_{\mathrm{CV}}^{2}: \mathrm{R}^{2}$ cross-validation; RMSEC - root mean square error of calibration; RMSECV - root mean square error of cross-validation.

$\left(\mathrm{R}^{2} \mathrm{CV}=0.76\right.$; $\left.\mathrm{RMSECV}=0.269 \mu \mathrm{g} \mathrm{g}^{-1}\right)$ showed promising results compared with the results of the reference method. The RPD is 2.04, which shows that the equation is suitable for qualitative determination. The lycoxanthin content was accurately predicted. The RMSECV is $0.281 \mu \mathrm{g} \mathrm{g}^{-1}$ and the number of the PLS factors are 7, which shows that the developed method is robust and applicable for lycoxanthin determination in tomato tissues. The PLS result for the determination of zeaxanthin content shows $\left(\mathrm{R}^{2} \mathrm{CV}=75.3\right.$; RMSECV $=0.099 \mu \mathrm{g} \mathrm{g}^{-1}$ ) that the NIR technique has the potential for the use in the determination of zeaxanthin content. In the case of $\beta$-carotene content determination, the NIR equation had a low RMSECV value $\left(0.174 \mu \mathrm{g} \mathrm{g}^{-1}\right)$ and high $\mathrm{R}^{2} \mathrm{CV}$ (0.89). The RPD is 2.95 , which shows that the model is applicable for quantitative analyses.

\section{CONCLUSIONS}

The traditional analyses are time-consuming with low sample throughput. The near-infrared technique is a costeffective and rapid technique for carotenoid measurement.

1. Analysis of NIR spectroscopy of cis-lycopene diepoxide, lycoxanthin and zeaxanthin was performed for the first time. The NIR spectral reflectances among tomato varieties or irrigation treatments were significant; the higher the water supply the lower the reflectance spectra were in every variety. Treatment combinations could interfere with those differences.

2. The models were developed by partial least square regression using a spectral range from $950 \mathrm{~nm}$ to $1650 \mathrm{~nm}$. The equations show that the near-infrared technique is able to predict carotenoid compounds with acceptable predictive error. 

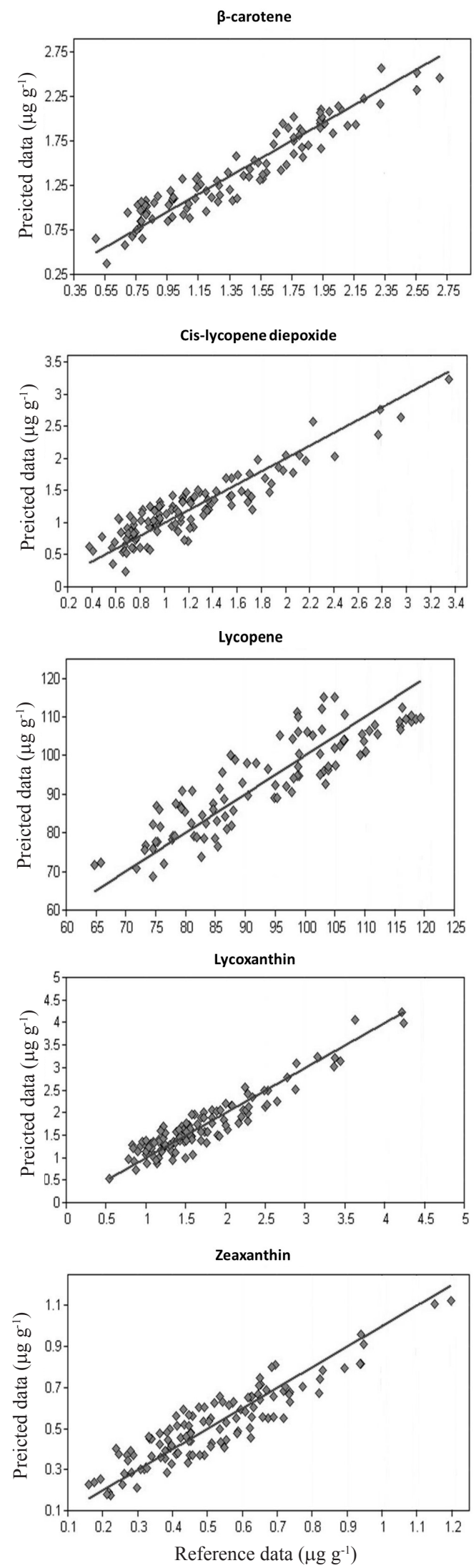

Fig. 2. References measured versus NIR predicted by the PLS model $(n=120)$.
3. The carotenoid composition of tomatoes can be determined by near-infrared spectroscopy coupled with partial least square regression models.

\section{REFERENCES}

Baranska M., Schutze W., and Schulz H., 2006. Determination of lycopene and beta-carotene content in tomato fruit and related products: Comparison of FT-Raman ATR-IR and NIR spectroscopy. Analytical Chemistry, 78, 8456-8461.

Bart M.N., Katrien B., Els B., Ann P., Wouter S., Karen I.T., and Jeroen L., 2007. Nondestructive measurement of fruit and vegetable quality by means of NIR spectroscopy: A review. Postharvest Biol. Technol., 46, 99-118.

Beecher R.G., 1998. Nutrient content of tomatoes and tomato products. Experimental Biology Medicine, 218, 98-100.

Belie N.D., Pedersen D.K., Martens M., Bro R., Munck L., and Baerdemaeker J.D., 2003. The use of visible and nearinfrared reflectance measurements to assess sensory changes in carrot texture and sweetness during heat treatment. Biosys. Eng., 85, 213-225.

Biacs P.A. and Daood H.G., 1994. High-performance liquid chromatography with diode-array detection of carotenoids and carotenoid esters in fruits and vegetables. J. Plant Physiol., 143, 520-525.

Borghesi E., González-Miret M.L., Escudero-Gilete M.L., Malorgio F., Heredia F.J., and Meléndez-Martínez A.J., 2011. Effects of salinity stress on carotenoids, anthocyanins, and color of diverse tomato genotypes. J. Agric. Food Chem., 59, 11676-11682.

Brandt S., Pék Z., Barna É., Lugasi A., and Helyes L., 2006. Lycopene content and colour of ripening tomatoes as affected by environmental conditions. J. Sci. Food Agric., 86, 568-572.

Britton G., Liaaen-Jensen S., and Pfander H., 2004. Carotenoids Handbook. Basel, Switzerland: Birkhäuser Verlag AG.

Clinton S.K., 1998. Lycopene: Chemistry, biology and implications for human health and disease. Nutrition Reviews, 56, 35-51.

Fiedor J. and Burda K., 2014. Potential Role of Carotenoids as Antioxidants in Human Health and Disease. Nutrients, 6, 466-488.

Flores K., Sánchez M.-T., Pérez-Marín D., Guerrero J.-E., and Garrido-Varo A., 2009. Feasibility in NIRS instrument for predicting internal quality in intact tomato. J. Food Eng., 91, 311-318.

Francis F.J., 2002. Food colorings. In: Colour in Food: Improving Quality (Ed. D.B. MacDougall). Woodhead Publishing, Limited Cambridge, England and CRC Press LLC, Boca Raton, FL, USA.

Helyes L., Dimény J., Pék Z., and Lugasi A., 2006a. Effect of the variety and growing methods as well as cultivation conditions on the composition of tomato (Lycopersicon lycopersicum (L.) karsten) fruit. Acta Horticulturae, 712, 511-516.

Helyes L., Lugasi A., and Pék Z., 2006b. Tomato fruit quality and content depend on stage of maturity. HortSci., 41, 1400-1401. 
Helyes L., Lugasi A., and Pék Z., 2012. Effect of irrigation on processing tomato yield and antioxidant components. Turkish J. Agric. Forestry, 36, 702-709.

Jha S.N. and Matsuoka T., 2004. Non-destructive determination of acid-brix ratio of tomato juice using near infrared spectroscopy. Int. J. Food Sci. Technol., 39, 425-430.

Karrer P. and Jucker E., 1950. Carotenoids. Elsevier Publishing Company Inc., New York, USA.

Matos H.R., di Mascio P., Medeiros M.H., 2000. Protective effect of lycopene on lipid peroxidation and oxidative DNA damage in cell cultures. Archives Biochemistry Biophysics, 383, 56-59.

Mercadante A.Z., 2008. Carotenoids in Foods: Sources and Stability during Processing and Storage In: Food colorants: chemical and functional properties (Ed. C. Socaciu). CRC Press, Boca Raton, FL, USA.

Oliveira De G. A., Bureau S., Renard C.M.-G.C., PereiraNetto A.B., and Castilhos De F., 2014. Comparison of NIRS approach for prediction of internal quality traits in three fruit species. Food Chemistry, 143, 223-230.

Pedro A.M.K. and Ferreira M.M.C., 2005. Nondestructive determination of solids and carotenoids in tomato products by near-infrared spectroscopy and multivariate calibration. Analytical Chemistry, 77, 2505-2511.

Pedro A.M.K. and Ferreira M.M.C., 2007. Simultaneously calibrating solids, sugars and acidity of tomato products using PLS2 and NIR spectroscopy. Analytica Chimica Acta, 595, 221-227.

Pék Z., Helyes L., and Lugasi A., 2010. Color changes and antioxidant content of vine and post-harvest ripened tomato fruits. HortSci., 45, 466-468.

Pék Z., Daood H., Lugasi A., Fenyvesi L., and Helyes L., 2014. Visible reflectance and content of isomeric ratio of lyco- pene in commercial and elevated lycopene tomato varieties by different technological traits. Acta Alimentaria, 43, 105-112.

Rao A.V. and Rao L.G., 2007. Carotenoids and human health. Pharmacological Res., 55, 207-216.

Rinnan Å., Nørgaard L., Berg F., van den Thygesen J., Bro R., and Engelsen S.B., 2009. Chapter 2 - Data Pre-processing. In: Infrared Spectroscopy for Food Quality Analysis and Control (Ed. D.-W. Sun). Academic Press, San Diego, CA, USA.

Rubio-Diaz E.D., Nardo D. T., Santos A., Jesus D.S., Francis D., Rodriguez-Saona E.L., 2010. Profiling of nutritionally important carotenoids from genetically-diverse tomatoes by infrared spectroscopy. Food Chem., 120, 282-289.

Saad A.G., Jaiswal P., and Jha S.N., 2014. Non-destructive quality evaluation of intact tomato using VIS-NIR spectroscopy. Int. J. Advanced Res., 2, 632-639.

Szigedi T., Lenart J., Dernovics M., Turza S., and Fodor M., 2012. Protein content determination in Brassica olaracea species using FT-NIR technique and PLS regression. Int. J. Food Sci. Technol., 47, 436-440.

Szuvandzsiev P., Helyes L., Lugasi A., Szántó C., Baranowski P., and Pék Z., 2014. Estimation of antioxidant components of tomato using VIS-NIR reflectance data by handheld portable spectrometer. Int. Agrophys., 28, 521-527.

Tianhua L., Guoying S., Jianmin W., Min W., and Jialin H., 2013. Prediction of lycopene content in late mature tomato based on NIR spectroscopy and siPLS. Int. J. Applied Mathematics and Statistics, 48, 172-180.

Tiwari G., Slaughter D.C., and Cantwell M., 2013. Nondestructive maturity determination in green tomatoes using a handheld visible and near infrared instrument. Postharvest Biology Technol., 86, 221-229. 